\title{
Identidade profissional e agir docente do professor de língua materna
}

\author{
José Cezinaldo Rocha Bessa ${ }^{1}$ \\ Franciclébia Nicolau da Silva ${ }^{2}$
}

\begin{abstract}
RESUMO
Quanto mais trabalhos surgem com a proposta de apontar e explorar as contribuições do pensamento bakhtiniano, sobretudo aquelas relacionadas ao ensino de língua materna no Brasil, mais visualizamos a necessidade de pesquisas e do empreendimento de renovadas discussões. Assim, visando aprofundar a compreensão sobre os eventos que se dão no tempo-espaço da relação entre professor e aluno em sala de aula, inclinamo-nos a escutar a voz do eu-professor, objetivando investigar como ele constrói sua identidade professoral e seu agir docente. Para tanto, solicitamos ao professor participante que elaborasse um caso de ensino, este correspondente a um tipo de narrativa reflexiva sobre o vivido em sala de aula. A perspectiva que fundamenta este trabalho corresponde ao diálogo construído entre as vozes do Círculo de Bakhtin e de outros estudiosos que discutem sobre o ensino de língua materna.
\end{abstract}

PALAVRAS-CHAVE: Contribuições bakhtinianas. Postura dialógica. Professor-aluno. Caso de ensino.

Professional identity and the teaching practice of mother tongue teacher

\begin{abstract}
The more work that comes out proposing to point out and explore the contributions of Bakhtin's thought, especially those related to mother tongue teaching in Brazil, the more we visualize the need for research and the undertaking of renewed discussions. Thus, in order to deepen our
\end{abstract}

\footnotetext{
${ }^{1}$ Doutor em Linguística e Língua Portuguesa pela Universidade Estadual Paulista Júlio de Mesquita Filho/Campus de Araraquara. Professor Adjunto IV da Universidade do Estado do Rio Grande do Norte/Campus de Pau dos Ferros, Pau dos Ferros, RN, Brasil. https://orcid.org/0000-0003-4655-6832. cezinaldobessauern@ gmail.com.

${ }^{2}$ Mestre em Ensino pela Universidade do Estado do Rio Grande do Norte/Campus de Pau dos Ferros, São João do Rio do Peixe, Paraíba, Brasil. https://orcid.org/0000-0001-7850-4055. clebianicos@hotmail.com.
} 
understanding of the time-space events of the teacher-student relationship in the classroom, we are inclined to listen to the voice of the teacher's self, aiming to investigate how she constructs her professorial identity and her teaching practice. In order to do so, we asked the participant teacher to elaborate a teaching case, which corresponds to a kind of reflective narrative about what is lived in the classroom. The perspective that underlies this paper corresponds to the dialogue built between the voices of the Bakhtin Circle and other scholars who discuss mother tongue teaching.

KEYWORDS: Bakhtinian contributions. Dialogical stance. Teacher Student. Teaching case.

\section{Introdução}

A construção deste artigo tem como motivação o tecido dialógico construído no conjunto de trabalhos que, no domínio dos estudos da linguagem e da educação, relaciona as contribuições bakhtinianos ao ensino de língua materna. Para citar alguns deles, mencionamos os trabalhos de Faraco e Castro (1999), Goldstein (2009), Pernambuco e Figueiredo (2011), Puzzo e Santos (2015), Geraldi (2015, 2017), Campos (2016) e Beloti e Menegassi (2017), pelos quais podemos identificar variadas relações/associações dos escritos do Círculo às práticas de linguagem (leitura, produção textual e análise linguística) e a aspectos diversos do trabalho com a língua materna em sala de aula.

Compartilhando das leituras dos estudiosos acima referidos e colocando-nos nesse tecido dialógico, acreditamos que o empreendimento de outras reflexões sobre experiências singulares, focalizando o contexto de sala de aula de língua materna, são oportunas e necessárias, para que, assim, possamos, além de dar voz aos sujeitos envolvidos na cena de cena de aula, aprofundar a compreensão sobre os eventos que se dão no espaço-tempo da relação entre professor e aluno. 
Para a reflexão tecida neste trabalho, inclinamos nossa escuta para a voz do eu-professor, objetivando aprofundar a compreensão sobre como este ser constrói sua identidade professoral e seu agir docente. Nesse sentido, tomamos como ponto de partida a narrativa do professor sobre si em plena comunicação discursiva com os outros, no caso, os alunos. A comunicação discursiva da qual falamos corresponde ao cotidiano da sala de aula de língua materna. Para tanto, orientamo-nos pela experiência vivida pelo professor e, por ele, considerada marcante para a sua vida como docente e ao processo de ensino-aprendizagem de seus alunos. Neste percurso, solicitamos ao professor participante dessa pesquisa que elaborasse um caso de ensino, aqui, correspondente a um tipo de narrativa reflexiva sobre a experiência do vivido em sala de aula.

Enformados teoricamente pela perspectiva dialógica do Círculo de Bakhtin, pretendemos, ademais, a partir desse caso, discutir sobre a importância de uma postura dialógica na relação professor-aluno, bem como para a produção do conhecimento em sala de aula de língua materna.

Com base em textos do Círculo de Bakhtin e de comentadores desse Círculo, construímos uma reflexão que parte da compreensão de que o narrar da experiência vivida constitui uma consciência material organizada de grande força social (VOLÓCHINOV, 2017). Além disso, somos levados a compreender esse tipo de experiência como uma forma de exercitar o movimento dialógico construído, também, no olhar exotópico que o eu realiza na sua relação com o outro (BAKHTIN, 2010a, 2010b). Desse modo, temos a oportunidade de escutar a voz do professor a partir do olhar que ele lança sobre sua própria experiência.

\section{Para expandir nossa compreensão sobre diálogo: o horizonte do Círculo de Bakhtin}

"A vida é dialógica por natureza" e "viver significa participar do diálogo" (BAKHTIN, 2010a, p. 348). Temos, nesses dizeres, um anúncio de 
que a concepção dialógica bakhtiniana constitui "[...] uma visão bem mais ampla, que comporta a ideia de consciência, de pensar, de sentir, de agir do sujeito, e de vida como constituídos por atos dialógicos” (BESSA, 2016, p.18). Assim, os sentidos construídos ao longo da vida, no inevitável (re)encontro das incontáveis vozes, permanecem como diálogos abertos ao infinito embate com outros contextos e sentidos de outras vidas, sujeitos e vivências, conforme enfatizado por Bakhtin (2017, p. 41):

O sentido é potencialmente infinito, mas pode atualizar-se somente em contato com outro sentido (do outro), ainda que seja com uma pergunta do discurso interior do sujeito da compreensão. Ele sempre deve contatar com outro sentido para revelar os novos elementos da sua perenidade [...].

Em nosso pequeno tempo, sobretudo aquele das relações cotidianas, construímos relações dialógicas as mais variadas, como, por exemplo, o diálogo que travamos com nós mesmos, com o "eu" que constitui cada um de nós, já que podemos nos converter em sujeitos outros nos diferentes espaçostempos. Em termos bakhtinianos, poderíamos falar de um ser autodialógico, um eu-para-mim, "[...] um discurso do falante que se reporta a sua própria fala" (BESSA, 2016, p. 23), que se revela como uma das faces do dialogismo. Por outro lado, podemos falar do diálogo entre enunciados desconhecidos, que "[...] se confrontados no plano do sentido (não como objetos e não como exemplos linguísticos), acabam em relação dialógica” (BAKHTIN, 2016, p. 92). Assim, percebemos um movimento possível pela liberdade da palavra, que pode chegar e ser recebida em qualquer lugar e por qualquer sujeito, desde que haja um colidir de vozes, as quais, concordantes e/ou discordantes, aprofundam o diálogo, uma vez que, este, não se faz apenas pelo pensar harmonioso.

É importante consideramos que, além de (re)conhecermos esse dialogismo como algo natural do ser humano, precisamos assumir tal 
natureza em meio às nossas ações cotidianas, posicionamentos e escolhas necessários ao nosso ato sempre responsivo e responsável. Essa seria uma postura dialógica diante da vida e pela qual se pode sair do fardo do eu-parasi (BAKHTIN, 2017) para perceber que escutar o outro constitui caminho para a construção do nosso próprio ser, para o aprofundamento da nossa visão sobre nós mesmos, sobre o outro, sobre o mundo. "Sem o outro, não há vozes. Sem o outro não há ecos” (GERALDI, 2005, p. 11). Revela-se aí uma transversalidade que estimula o viver para ser mais, para sermos outros com/pelos outros sem que nos perdamos no lugar do eu único, já que, por assim dizer, "O eu se esconde no outro e nos outros, quer ser apenas outro para os outros, entrar até o fim no mundo dos outros como outro, livrar-se do fardo de eu único (eu-para-mim) no mundo." (BAKHTIN, 2017, p. 43, grifos do autor). Esse é o jogo dialógico correspondente ao movimento que eclode em uma, nem sempre, harmoniosa arquitetônica completa do movimento dialógico:

Minha imagem de mim mesmo. Qual é a índole da concepção de mim mesmo, do meu eu em seu todo? Em que ele se distingue essencialmente da minha concepção do outro? A imagem do eu ou o conceito, ou o vivenciamento, a sensação, etc. [...] O que compreendo por eu quando falo e vivencio: "eu vivo", "eu morro", etc. (“eu sou”, “eu não existirei”, “eu não existi”). Eu-para-mim e eu-para-o-outro, o outro-para-mim. [...]. (BAKHTIN, 2017, p. 42, grifos do autor).

Bakhtin está falando de um eu que, inevitavelmente, em meio a um movimento exotópico em relação a si e ao outro, tenta construir uma compreensão do seu próprio eu em relação ao seu-outro. Desse modo, na possibilidade de compreensão se dá o alargamento/aprofundamento da consciência do sujeito. Estamos participando, assim, de um profundo e eterno diálogo que nos faz viver inacabadamente. 
Diante disso, o sujeito bakhtiniano é, pois, um ser em construção, um ser que aprofunda a sua consciência no embate de vozes e no agir nas/entre as diferentes esferas da atividade humana. Assim, ele poder ser sempre outro, posto que é visto como um ser sempre inconcluso. Para essa compreensão, direcionemo-nos à concepção bakhtiniana de linguagem. A linguagem que nos insere no contínuo diálogo. Por isso, a necessidade de relacioná-la à vida, esta construída no tempo e no espaço da nossa inconclusão. Um ponto de vista que nos faz refletir sobre a natureza real, concreta, dialógica e ideológica daquilo que nos faz construir sentidos no mundo. Nesse sentido, não há como, nem por que, restringir a linguagem ao aspecto puramente verbal, uma vez que ela é a palavra enquanto fenômeno ideológico (VOLÓCHINOV, 2017).

E na função de ser signo da palavra, entramos no campo da significação, pelo qual e com o qual a palavra tem sua representatividade enquanto fenômeno ideológico, sempre axiologicamente valorada. Por assim dizer, a dialogicidade natural da linguagem é uma concepção fundante nas obras de Bakhtin; é a célula geradora daquilo que mantém singular e pulsante o pensar bakhtiniano (BRAIT, 1994).

\section{Procedimentos metodológicos: o caso de ensino}

Conforme descrito na parte introdutória deste trabalho, utilizamo-nos do ato de narrar sobre si do professor como meio de compreensão da sua voz, da experiência vivida no cotidiano da sala de aula de língua materna.

No caminho percorrido para o desenvolvimento desta pesquisa deparamo-nos com estudos sobre formação docente e sobre os instrumentos possíveis para o desenvolvimento, investigação e reflexão da/sobre prática do professor. Assim, surgiu a possibilidade de encontrarmos os casos de ensino como produções discursivas motivadas por um dizer sobre si mesmo. Destaque-se, neste âmbito, os casos de ensino apresentados na pesquisa 
desenvolvida por Duek (2011). A pesquisadora considera que os casos de ensino podem oferecer

[...] aos docentes que atuam na escola regular a oportunidade para que venham refletir sobre diferentes aspectos de sua atuação em sala de aula e para sistematizar seus conhecimentos profissionais, constituindo-se em poderoso instrumento para a aprendizagem e para o desenvolvimento profissional de professores. (DUEK, 2011, p. 70).

Além disso, enquanto pesquisadores, avaliamos que as narrativas produzidas sob o olhar construído por esses casos de ensino são instrumentos poderosos, também, para a nossa investigação e compreensão do discurso sobre a própria prática docente, neste momento, do professor de língua materna. Neste sentido, ter como meio de investigação narrativas corresponde para nós um potencial processo de investigação, uma vez que corroboramos com a concepção de que

Nós não aprendemos a partir da experiência; nós aprendemos pensando sobre nossa experiência... [...] Um caso é uma versão relembrada, recontada, reexperenciada e refletida de uma experiência direta. O processo de relembrar, recontar, reviver e refletir é o processo de aprender pela experiência. (SHULMAN, 1996, p. 208).

As palavras de Shulman (1996) reforçam o processo de narrar e refletir a experiência como uma ferramenta de autodesenvolvimento profissional muito produtiva. Em termos bakhtinianos, poderíamos pensar em cronotopo e exotopia, uma vez que narrar o vivido pode ser compreendido como um encontro com um discurso, único, singular, particular e pelo qual somos inseridos na realidade fundamental da língua em sua integridade concreta e viva (BAKHTIN, 2010c), o acontecimento social da interação 
discursiva (VOLÓCHINOV, 2017), e, neste caso, possibilitada pelas valorações ressignificadas diante do intento de falar sobre si com outros.

Diante disso, uma pesquisa que se fundamenta no escutar a voz do outro, neste caso, através da narrativa do professor sobre algo experenciado, configura-se enquanto processo de formação profissional tanto para o pesquisador quanto para o pesquisado, que, por conseguinte, pode ser visto como um pesquisador ou se constrói como tal, também, ao narrar uma experiência do vivido enquanto ato responsável e responsivo (BAKHTIN, 2010a, 2010b). Narrar uma experiência do vivido é, pois, dar uma resposta à ação realizada no mundo.

Uma vez considerados os direcionamentos referidos sobre investigação narrativa e caso de ensino, passemos a descrever, a seguir, como foi coletado o caso de ensino por nós analisado.

O contato com o professor de língua materna que produziu o caso de ensino foi estabelecido no próprio ambiente escolar no mês de agosto do ano de 2017. A conversa com o docente foi centrada na explicação sobre a elaboração do caso de ensino, desde que houvesse disponibilidade para ele. Foi proposta a produção de uma narrativa sobre alguma experiência vivida com os alunos de determinado ano/série e que considerasse ter sido significativa para a sua formação enquanto professor, bem como para o processo de ensino-aprendizagem dos alunos. A experiência poderia ser de algo ocorrido em anos anteriores ou no ano do nosso contato. O prazo acordado para a entrega foi de quinze dias.

No caso de ensino, o docente poderia relatar e refletir as ações planejadas e executadas para o andamento da atividade que desejasse narrar, as dificuldades encontradas, os fatores que contribuíram para o bom desenvolvimento ou qualquer outro aspecto, considerado, pelo professor, importante e necessário deixar expresso. Ao final, pedimos que formulasse um título para a sua narrativa.

Finalizado o prazo combinado para a produção do relato, estabelecemos novo contato para a entrega. Recebemos uma via digitada 
impressa no dia 30 de agosto de 2017. Após a leitura do caso, reestabelecemos o contato para que pudéssemos conversar sobre o caso de ensino produzido. Na ocasião, três questionamentos foram postos: (i) Professor, por que escolheu relatar esta experiência? (ii) Como se sentiu ao relatar algo desenvolvido por você na sala de aula? (iii) Que aprendizado(s) você tirou dessa experiência com os alunos? Este momento com o professor ocorreu no seu ambiente de trabalho no dia 05 de setembro de 2017.

Como se pode observar, as perguntas perfazem saberes sobre a experiência vivenciada pelo professor com seus alunos e sobre a importância da narração/reflexão de um acontecimento em sala de aula. Esse instante surgiu como um importante instrumento de aprofundamento do nosso olhar sobre a narrativa desenvolvida.

O olhar de analista que construímos sobre esse caso de ensino tem, portanto, na orientação interpretativa de pesquisa, seu direcionamento de investigação. Dada a assunção desse direcionamento, bem como a natureza do material analisado, a abordagem qualitativa de pesquisa permeia o enfrentamento analítico do caso de ensino escolhido.

\section{O caso de ensino: escutar para compreender}

A seguir o caso de ensino elaborado pelo professor, na íntegra, e, posteriormente, alguns questionamentos, sobre os quais já nos referimos. Vejamos:

1) O caso de ensino

\section{O cordel enquanto manifestação da cultura e da língua de nossa gente ${ }^{3}$}

Sou professor de Língua Portuguesa há oito anos, desde então ministro aulas tanto no Ensino Fundamental como no Ensino Médio. Sou graduado em Letras - Língua Materna e pós-graduado em Língua Portuguesa (especialização) e em Letras (Mestrado Profissional). Há quatro anos sou professor efetivo da rede

\footnotetext{
${ }^{3}$ Titulo atribuído pelo professor ao seu caso de ensino.
} 
pública estadual de ensino e há três anos faço parte do quadro efetivo de professores da rede pública municipal. $\mathrm{O}$ caso de ensino que irei relatar ocorreu na escola municipal localizada na zona rural da cidade onde trabalho, durante o primeiro semestre deste ano de 2017.

Já fazia parte do meu plano anual desenvolver um trabalho como esse, porém, resolvi antecipar devido à solicitação por parte da coordenação da escola em desenvolver alguma atividade com os alunos que tivesse como tema central a proposta da Campanha da Fraternidade 2017, que tem como tema: Fraternidade biomas brasileiros e defesa da vida e lema: Cultivar e guardar a Criação.

Ao pensar a atividade a ser desenvolvida com os alunos, decidi antecipar o trabalho de produção textual que iria realizar posteriormente com o gênero cordel. Percebi que poderíamos produzir um trabalho bem significativo, já que a Campanha da Fraternidade trata dos biomas como tema e, sendo o nosso bioma o da caatinga, pensei que os alunos teriam um momento bem oportuno para refletir sua cultura, a nossa língua, o povo e, com isso, conhecer a força, mas, também, as fragilidades de nosso torrão. Neste quadro, o gênero cordel poderia fazer com que os alunos produzissem um conhecimento valioso sobre o sertão enquanto tempo e espaço de cultura. A turma com a qual trabalhei foi a do $9^{\circ}$ ano.

A etapa inicial dessa atividade foi conversar com os alunos sobre a proposta da coordenação e o que eu estava planejando fazer com eles. Prontamente eles demonstraram interesse e muita animação em estudar o cordel, que, também, era um tanto quanto novo para mim, já havia lido muitos cordéis e sempre fui admirador desse tipo de produção, mas passar a ensinar o gênero, a fazer com que os alunos tivessem algum conhecimento mais aprofundado, era algo novo na minha profissão. Passei a me aprofundar mais por conta dessa atividade. Eu aprendi muito junto com eles. A partir disso achei importante trabalhar a leitura em voz alta para eles atentarem ao ritmo presente nesses textos. Levei cordéis com temáticas sobre o sertão, assistimos a vídeos sobre cordel, cordelistas e a arte de fazer xilogravuras. Em momento anterior havia trabalhado com esses alunos a produção de poemas com foco na conexão das ideias para a rima e o ritmo empregados e necessários para a construção desses poemas.

O conhecimento trabalhado nesses poemas foi retomado com o estudo dos cordéis e fez com que avançássemos bastante nessa atividade, pois a rima e o ritmo são duas das características principais na produção do gênero discursivo cordel. 
Para dar continuidade a essa etapa, realizei algumas dinâmicas que tinham como objetivo compreender o caráter essencial do ritmo e da rima presente nesse gênero. Esses foram outros momentos de grande animação por parte dos participantes, incluindo a mim, claro.

A interação foi muito importante em todo o processo, especialmente, o da escrita e reescrita dos textos. O momento da reescrita foi realizada em grupos, cada um tinha a tarefa de ler os textos dos outros colegas e dar sugestões para a melhoria das histórias. Essa etapa não foi fácil, principalmente, porque boa parte estava preocupada em acertar a gramática, deixando de lado o sentido e a progressão da história a ser desenrolada em seus textos. Eles estavam bem preocupados nesse sentido, o que acabou bloqueando a inspiração de muitos deles. Com o desenrolar das discussões, eles passaram a compreender que esse gênero possibilita a presença de marcas informais da fala dos sujeitos, desde que seja a intenção do autor empregar tais marcas. Aos poucos, e com sugestões coletivas, todos foram produzindo seus cordéis. Ao final, fomos observando os empregos informais da língua que eles foram atribuindo aos personagens das histórias e verificando a intenção deles ao empregarem essas marcas.

Os alunos chegavam a todo momento para relatar a satisfação com essa atividade, que seria impressa e divulgada para todos da escola. É fato que dificuldades surgiram, a começar pela falta de material necessário para fazer as xilogravuras com os alunos. Para isso, comprei a maior parte dos instrumentos necessários para a execução dessa tarefa como a tinta e os isopores. Essa fase foi muito satisfatória, o desenho das xilogravuras foi outro momento em que eles demonstraram prazer ao realizarem. Eles se empenharam bastante para fazer tudo da melhor forma possível. Outras dificuldades foram o tempo corrido das aulas e, ainda, a necessidade de finalizar a atividade a tempo para a culminância de um projeto maior desenvolvido na escola, porém, esse tipo de coisa acaba virando rotina no nosso trabalho, porque é o que temos na maioria das vezes. Mas acredito que devemos ter em mente que o nosso trabalho não pode parar diante dessas dificuldades.

Como produto final os alunos produziram seis cordéis, alguns em dupla, trios ou individualmente. Os mesmos foram reunidos em um único livreto denominado: Eu, poeta da terra e da minha gente. Outra dificuldade foi com relação à impressão desses livretos, pois a escola não dispunha de dinheiro para 
isso e, mais uma vez, para não ver o trabalho estancar, encomendei a impressão desses livretos por conta própria. No dia da culminância do projeto maior, houve a apresentação desse trabalho com a leitura dos cordéis feita pelos próprios alunos que os produziram. Os alunos tiveram a oportunidade de vender os cordéis e arrecadar uma quantia que seria utilizada para a festa de conclusão do Ensino Fundamental que eles estão organizando. É muito importante esse momento da partilha, quando todos da comunidade escolar tomam ciência dos trabalhos realizados no contexto escolar.

2) Diálogo com o docente: perguntas e respostas

\section{- Professor, por que escolheu relatar esta experiência?}

Esse momento ficou marcado muito positivamente na minha mente. Até então não havia realizado nenhum trabalho com o cordel e os alunos também não haviam feito algo assim. Fiquei muito feliz com a boa recepção dessa atividade com os meus alunos do $9^{\circ}$ ano. É um trabalho que pretendo realizar sempre. Precisamos conhecer mais nosso povo, nossas histórias, as marcas culturais e manifestações linguísticas da nossa gente. Esse caso de ensino proporcionou isso para todos nós.

\section{" Que aprendizado(s) você tirou dessa experiência com os alunos?}

Aprendi que precisamos escutar mais nossos alunos, muitas outras ideias surgiram durante essa atividade, algumas com certo ar de tristeza, porque essa turma, ou a maior parte dela, sairá da escola para iniciar outra fase de estudos no Ensino Médio. Aprendi que podemos pensar atividades que motivem os alunos. Não temos como fugir dos conteúdos já previstos no currículo, mas isso não quer dizer que não podemos fazer nada além deles. O livro não trazia o trabalho com o cordel em sala de aula, mas pensei, planejei e deu certo. Atividades como essa, em que os alunos são instigados a interagir uns com os outros são trabalhosas, sim, mas são muito mais significativas. Eu sempre aprendo muito com esses momentos.

- Como se sentiu ao relatar algo desenvolvido por você na sala de aula?

Não pensei que fosse gostar tanto. É bem diferente quando passamos a refletir para escrever algo que produzimos com nossos alunos para alguém. Esse 
momento de parar para lembrar algo que não ficou nos registros escritos e nas fotografias faz a gente pensar bastante sobre o que fizemos. É uma oportunidade que todo professor poderia se dar em algum momento da sua vida. Acredito que não teria feito isso se não fosse esse convite. Fiquei feliz por ter aceitado. É um momento de reflexão muito bom.

\section{Compreendendo e expandindo os horizontes sobre o caso de ensino}

O caso de ensino: o cordel enquanto manifestação da cultura e da língua de nossa gente (título atribuído pelo professor) constitui-se como uma narrativa reflexiva em que um professor de língua portuguesa do ensino médio detalha uma situação que ele vivenciou durante o primeiro semestre de 2017. A produção textual realizada com os alunos foi uma atividade que o professor planejou para o ano, no entanto, foi, segundo ele, antecipada devido à solicitação de ações a serem desenvolvidas pelos professores em função da Campanha da Fraternidade do ano de $2017^{4}$ e pensada com base em questões sociais consideradas de forte apelo popular, conforme destacou o professor quando no último contato estabelecido. Por esse motivo, é comum presenciar a abordagem de temas desenvolvidos por essas campanhas em muitos contextos escolares como modo de informação e conscientização da comunidade sobre essas questões.

Diante disso, ressaltemos a postura do professor ao tentar desenvolver um trabalho significativo no âmbito da referida campanha, levando seus alunos a realizarem algo que os aproximassem do espaçotempo próprios, no caso, o sertão paraibano significado por eles naquele momento. Temos, pois, uma maneira que o docente encontrou para associar uma atividade proveniente de uma solicitação externa, uma vez que não surgiu propriamente de seu plano, àquilo que percebeu ser condizente com uma atividade na área de linguagem e, por isso, acentuada como bastante produtiva. Vejamos sua fala:

\footnotetext{
${ }^{4}$ O lema da referida campanha para o ano de 2017 foi "Cultivar e guardar a Criação".
} 
Percebi que poderíamos produzir um trabalho bem significativo, já que a Campanha da Fraternidade trata dos biomas como tema e, sendo o nosso bioma o da caatinga, pensei que os alunos teriam um momento bem oportuno para refletir sua cultura, a nossa língua, o povo e, com isso, conhecer a força, mas, também, as fragilidades de nosso torrão.

Neste sentido, vemos a importância de o professor de língua materna elaborar estratégias de ensino que pensem o estudo da língua enquanto concreta e viva e, com isso, construir uma realidade (re)significada para seus alunos no ambiente escolar. Essa significação, quanto ao ser aluno, pode ser observada quando o professor diz: "pensei que os alunos teriam um momento bem oportuno para refletir sua cultura, a nossa língua, o povo e, com isso, conhecer a força, mas, também, as fragilidades de nosso torrão." Há, pois, um deslocamento, a partir do qual o professor constrói uma identidade para esse aluno, uma identidade relacionada ao lugar em que se encontram, à cultura na qual estão inseridos, a sua realidade mais próxima.

A visão de texto que se percebe relaciona-se à visão de língua referida. Diante disso, consideramos que há uma compreensão de texto que ultrapassa o material linguístico para chegar ao discurso e, dessa forma, ao encontro da identidade construída por essas relações dialógicas, por aquilo que professor, alunos e outros produziram e significaram juntos no processo de comunicação discursiva. Neste âmbito, destacamos indícios de que os alunos foram levados a refletir, dentre outras questões, sobre o sujeito produtor do enunciado (o cordelista), a situação de produção, as motivações que levaram o sujeito autor a elaborar tal projeto de dizer, a refletir sobre as características elementares à produção do gênero cordel.

A conversa que disse ter feito com os alunos para tratar da campanha, das demandas da escola e do que iriam realizar remete-se a um diálogo aberto a sugestões de todos. Esse tipo de agir docente pode ser pensado por 
todo professor quando se põe a pensar e a comunicar suas "propostas", no que se refere às atividades que pretende realizar em sala, que nem sempre surgem como proposições. É fato que, ao docente, são atribuídos muitos deveres, a começar pelos caminhos que precisa programar para todo o decorrer do ano letivo, no entanto, esse dever "maior" não pode engessar ou impedir um trabalho docente fundamentado na construção de sentidos.

Diante da realidade descrita e valorada pelo professor, percebe-se uma inclinação para a escuta: "A etapa inicial dessa atividade foi conversar com os alunos sobre a proposta da coordenação e o que eu estava planejando fazer com eles". Além disso, destacamos sua disponibilidade em trabalhar uma atividade na qual disse sentir certa insegurança, mas que demonstrava esforço em aprender, em aprender junto com os seus alunos. Parece ter sido o que ocorreu com ele, quando declarou não ter tanto conhecimento sobre o gênero, pelo menos não como um produtor, mas, sim, enquanto leitor.

Reforcemos, neste momento, o ser professor como um eterno aprendiz e, por isso, a necessidade de ele reconhecer o tempo e o espaço da sala de aula como instantes de constantes transformações, bem como os momentos em que ele se dedica a pensá-la como a continuidade necessária ao seu agir. Por assim dizer, o professor não se forma como tal na graduação, ele tornase e continua professor na sala de aula e/ou nos momentos em que ele se mantém inclinado para esse acontecimento e, portanto, para o outro: o seu aluno. Sendo assim, destacamos a palavra do professor quando se expressa: "Passei a me aprofundar mais por conta dessa atividade. Eu aprendi muito junto com eles." Por esse caminho, percebemos o ensino enquanto processo. Disso, surge a necessidade de atividades que possam ser fundamento para outras, que possibilitem reflexões várias para outras ações.

Sobre este aspecto, destaquemos uma ação anterior ao trabalho dos cordéis: a produção de poemas rimados, que retornou como um conhecimento fundamental para o avanço do caso ilustrado, já que uma das 
características básicas do cordel havia sido trabalhada anteriormente pelo professor.

Em momento anterior havia trabalhado com esses alunos a produção de poemas com foco na conexão das ideias para a rima e o ritmo empregados e necessários para a construção desses poemas. Esse conhecimento foi retomado com o estudo dos cordéis.

O foco atribuído parece ter sido uma real e mais aprofundada interação entre os sujeitos construtores da realidade narrada e, com isso, a (re)construção do conhecimento pela situação de comunicação estabelecida durante esse trabalho, que tende a ser viva, concreta e real e iniciada pelo contexto dos sujeitos daquela situação de comunicação. Nesse percurso, cumpre destacar o processo de reescrita dos cordéis descrito:

A interação foi muito importante em todo o processo, especialmente, o da escrita e reescrita dos textos. $O$ momento da reescrita foi realizada em grupos, cada um tinha a tarefa de ler os textos dos outros colegas e dar sugestões para a melhoria das histórias. Essa etapa não foi fácil.

A reescrita de textos em atividades de produção textual é sabidamente um ponto delicado, o "calcanhar de Aquiles" de muitos professores de língua. Pela fala, percebemos a dificuldade de tentar um trabalho de reescrita com foco na construção coletiva do conhecimento, em que, inicialmente, os primeiros leitores dos textos foram os próprios colegas da turma e, posteriormente, os que dariam as sugestões de mudança e melhoria. Neste âmbito, mais uma vez, atentamos para a importância da mediação do professor em todo o processo.

Sobre as dificuldades, estas são significadas como sendo inevitáveis no cotidiano escolar, porém, não podendo (ou não devendo) tornar o trabalho impossível. As dificuldades descritas neste caso vão desde o desenvolvimento 
das estratégias de ensino a outras de cunho material e financeiro. Conforme lemos, o docente utilizou recursos próprios para a compra de parte do material para a produção das xilogravuras, bem como para a divulgação impressa dos cordéis. Neste dizer, destacamos uma realidade escolar não muito difícil de ser encontrada em outros contextos e que o professor sentiu a necessidade de se expressar quanto aos obstáculos que ele encontrou no caminho. Assim, a ideia de superação, por parte de professores, alunos e das adversidades que atravessam a realidade escolar brasileira é ainda assumida e valorada de modo positivo, no dizer do professor. Neste âmbito, atentemos para a relação de submissão do professor diante do tempo que acabou sendo (im)posto ao seu trabalho e ressignificado, no caso de ensino, como mais uma dificuldade por ele enfrentada:

Eles se empenharam bastante para fazer tudo da melhor forma possível. Outras dificuldades foram o tempo corrido das aulas e, ainda, a necessidade de finalizar a atividade a tempo para a culminância de um projeto maior desenvolvido na escola, porém, esse tipo de coisa acaba virando rotina no nosso trabalho [...].

Outro aspecto que merece destaque diz respeito à proposta de divulgação impressa dos cordéis. Os alunos, muitas vezes, desenvolvem alguma produção escrita por simples obrigação (im)posta por professores. Decerto, proporcionar aos alunos um momento de reconhecimento por parte da comunidade escolar pode ser um fato mobilizador, aspecto sobre o qual o professor procura colocar um acento valorativo positivo.

Com isso, os alunos tomaram consciência de que outros, além do professor, conheceriam aquele trabalho. Entendemos, pois, que possibilitar aos alunos o desenvolvimento de uma atividade de produção textual que vá além do diálogo estabelecido entre os interlocutores, professor e alunos, como a descrita aqui, deve ser encarada como uma atitude responsável e responsiva daquele que se propõe a refletir, com seus alunos, sobre a língua 
que os significam. É, pois, uma abertura para novos horizontes, para outros caminhos metodológicos ressignificadores da produção dialógica do conhecimento nas aulas de língua materna.

\section{Considerações finais}

Nossa intenção, com esse trabalho, foi escutar, compreender, interpretar um discurso, único, singular e próprio de um professor de língua materna sobre um trabalho desenvolvido em sala de aula e que, de algum modo, marcou valorativamente sua vida (cronotopicamente) e a vida dos alunos (exotopicamente). Nossa leitura permitiu compreender que não podemos dizer como se construiu a identidade professoral deste sujeito, com o qual mantivemos contato pelo dado analisado, uma vez que o que temos é um recorte, um dado singular, um pedaço do mundo desse sujeito, para o qual atribuímos sentidos-outros.

Podemos, sim, considerar, a partir dos indícios encontrados em sua narrativa, que o trabalho desenvolvido foi, para ele, significativo à sua formação, à sua identidade, e (re)colocado, (re)valorado no momento em que se dispôs a narrar e a refletir sobre esse acontecimento. Por isso, para nós, essa identidade professoral não é, ela se dá, se constrói, ela continua, assim como é o sujeito bakhtininiano: (in)completamente inacabado. E nesse inacabamento surge uma proposta: a produção de um caso de ensino, de uma narrativa, de um discurso, em meio a tantos outros que contribuíram/contribuem para a sua formação e constituição do seu ser professor.

Assim, com essa escuta que empreendemos aqui, esperamos contribuir de alguma forma para a teia dialógica em que se inserem as pesquisas com narrativas do vivido em sala de aula enquanto etapa para o autodesenvolvimento profissional, portanto, para a formação de professores de língua materna, bem como para as pesquisas no âmbito das ciências 
humanas, especialmente naquelas inseridas na interface dos domínios da linguagem e da educação.

\section{Referências}

BAKHTIN, M. M. Estética da criação verbal. Tradução do russo de Paulo Bezerra. 5. ed. São Paulo: Martins Fontes, 2010a.

BAKHTIN, M. M. Para uma filosofia do ato responsável. Tradução aos cuidados de Valdemir Miotello \& Carlos Alberto Faraco. São Carlos: Pedro \& João Editores, 2010b.

BAKHTIN, M. M. Problemas da poética de Dostoiévski. Tradução de Paulo Bezerra. 5. ed. Rio de Janeiro: Forense Universitária, 2010c.

BAKHTIN, M. M. Os gêneros do discurso. Organização, tradução, posfácio e notas de Paulo Bezerra. São Paulo: Editora 34, 2016.

BAKHTIN, M. M. Notas sobre literatura, cultura e ciências humanas. Organização, tradução, posfácio e notas de Paulo Bezerra. São Paulo: Editora 34, 2017.

BELOTI, A.; MENEGASSI, R. J. A constituição teórica, metodológica e prática sobre revisão e reescrita na formação docente inicial-PIBID. Diálogo das Letras, Pau dos Ferros, v. 06, n. 01, p. 9-32, jan./jun. 2017. Disponível em:< http://periodicos.uern.br/index.php/dialogodasletras/article/view/2396/1306>.

Acesso em: 25 maio 2018.

BESSA, J. C. R. Das múltiplas facetas do dialogismo bakhtiniano: reflexões teóricas e um percurso analítico de estudo. In: FERREIRA, F. A.; LUDOVICE, C. A. B.; PERNAMBUCO, J. (Org.). O texto: processos, práticas e abordagens teóricas. 1ed.Franca, SP: Editora UNIFRAN, 2016, v. 1, p. 10-31.

BRAIT, B. As vozes bakhtinianas e o diálogo inconcluso. In: BARROS, D. L. P.; FIORIN, J. L. (Orgs.). Dialogismo, polifonia, intertextualidade. São Paulo: EDUSP, 1994, p. 11-27.

CAMPOS, M. I. B. Bakhtin e o ensino de língua materna no Brasil: algumas perspectivas. Conexão Letras, v. 11, n. 16, p. 123-137, 2016. Disponível em: <http://seer.ufrgs.br/index.php/conexaoletras/article/view/70359/39817>. Acesso em: 25 mai. 2018.

DUEK, V. P. Educação inclusiva e formação continuada: contribuições dos casos de ensino para os processos de aprendizagem e desenvolvimento profissional de professores. 2011. 349 f. Tese (Doutorado em Educação) - Universidade Federal do Rio Grande do Norte, Natal, 2011.

FARACO, C. A.; CASTRO, G. de. Por uma teoria lingüística que fundamente o ensino de língua materna (ou de como apenas um pouquinho de gramática nem 
sempre é bom). Educ. rev., v. 15, n. 15, p.109-117, 1999. Disponível em: $<$ https://revistas.ufpr.br/educar/article/view/2061/1713>. Acesso em: 25 mai. 2018.

GERALDI, J. W. A linguagem em Paulo Freire. Educação, Sociedade \& Culturas, n. 23, p. $7-20,2005$.

GERALDI, J. W. O ensino de língua portuguesa e a Base Nacional Comum Curricular. Revista Retratos da Escola, Brasília, v. 9, n. 17, p. 381-396, jul./dez. $2015 . \quad$ Disponível em: $<$ http://retratosdaescola.emnuvens.com.br/rde/article/view/587/661>. Acesso em: 25 mai. 2018.

GERALDI, J. W. Passando em revista ideias sobre o ensino de língua portuguesa: uma entrevista com João Wanderley Geraldi. Diálogo das Letras, Pau dos Ferros, v. 6, n. $1, \quad$ p. 490-496, jan./jun. 2017. Disponível em: $<$ http://periodicos.uern.br/index.php/dialogodasletras/article/view/2433>. Acesso em 20 maio 2018.

GOLDSTEIN, N. S. Gêneros do discurso e gramática no ensino de língua materna. SCRIPTA, Belo Horizonte, v. 13, n. 24, p. 95-109, $1^{\circ}$ sem. 2009. Disponível em: $<$ http://periodicos.pucminas.br/index.php/scripta/article/view/4397/4558>. Acesso em: 25 mai. 2018.

PERNAMBUCO, J.; FIGUEIREDO, M. F. Contribuições bakhtinianas para o ensino da gramática. Estudos Linguísticos, São Paulo, v. 40, n. 2, p. 682-696, maiago 2011. Disponível em: <https://revistas.gel.org.br/estudoslinguisticos/article/view/1329/873>. Acesso em: 25 mai. 2018.

PUZZO, B. M.; SANTOS, S. S. B. Gênero discursivo e as novas linguagens no ensino de língua portuguesa. Linha D'Água (Online), São Paulo, v. 28, n. 2, p. 2643, $\operatorname{dez} 2015 . \quad$ Disponível em: <http://www.revistas.usp.br/linhadagua/article/view/102989/106320>. Acesso em: 25 maio 2018.

SHULMAN, L. Just in case: reflections on learning from experience. In: COLBERT, J., TRIMBLE, K., AND DESBERG, P. Ed. The case for education: contemporary approaches for using case methods. Needham Heights, Massachusetts: Allyn \& Bacon, 1996, p. 197-217.

VOLÓCHINOV, V. N. Marxismo e filosofia da linguagem: problemas fundamentais do método sociológico na ciência da linguagem. Tradução, notas e glossário de Sheila Camargo Grillo e Ekaterina Vólkova Américo. São Paulo: Editora 34, 2017.

Recebido em setembro de 2018.

Aprovado em junho de 2019. 